\title{
Nitidine chloride inhibits the appearance of cancer stem-like properties and regulates potential the mitochondrial membrane alterations of colon cancer cells
}

\author{
Hongyan Gong ${ }^{1}$, Li Wang ${ }^{1}$, Jing Zhao ${ }^{2}$, Lixin Wang ${ }^{1}$, Qiangzong Yu ${ }^{1}$, Yong Wan ${ }^{1}$ \\ ${ }^{1}$ Gastrointestinal Surgery, Yantaishan Hospital, Yantai 264001, China; ${ }^{2}$ Department of Intravenous Medication, West Campus of Zibo Central \\ Hospital, Zibo 255020 China \\ Contributions: (I) Conception and design: H Gong, Y Wan; (II) Administrative support: L Wang, L Wang; (III) Provision of study materials or \\ patients: H Gong, L Wang, Q Yu; (IV) Collection and assembly of data: All authors; (V) Data analysis and interpretation: H Gong, L Wang, Y Wan; \\ (VI) Manuscript writing: All authors; (VII) Final approval of manuscript: All authors. \\ Correspondence to: Yong Wan. Gastrointestinal Surgery, Yantaishan Hospital, No. 91, Jiefang Road, Zhifu District, Yantai 264001, China. \\ Email: zdesheng001@163.com.
}

Background: Nitidine chloride (NC) is a natural alkaloid that can inhibit tumor growth and induce apoptosis in varieties of cancers. However, the effec12/268t of NC on colon cancer (CC) cells has not been extensively studied.

Methods: Conlon cancer SW480 cells was treated with different concentrations of NC $(0.25,0.5,1,2.5$, $5,10,25,50,100$, and $200 \mu \mathrm{M})$ in DMEM medium for 24 hours. Western blotting (WB) was used to detect the expression of related proteins, such as Ki67, PCNA, NANOG, SOX2, OCT4, Bcl-2, Bax, Caspase-3, Caspase-9, ERK1/2, p-ERK1/2, AKT, p-AKT, STAT3, p-STAT3, P65 and p-P65. The pellet formation experiment was used to detect the pellet formation of stem cells. The JC-1 experiment was used to detect the change of mitochondrial membrane potential. Kit was performed to detect the activity of superoxide dismutase (SOD) and the content of malondialdehyde (MDA). In vivo experiments were used to verify the results of in vitro experiments. TUNEL assay was designed to detect the apoptosis in mice tissue. IHC was used to detect expression of Ki67 and OCT4 protein in tissue.

Results: NC significantly inhibited the expression levels of Ki-67 and a proliferating cell nuclear antigen (PCNA). NC can reduce the pellet colony and pellet size of tumor stem cells and block the stem cell characteristics of CC cells. The corresponding stem cell marker molecules NANOG, SOX2, and OCT4 were also downregulated. NC treatment induced the mitochondrial membrane potential depolarization of CC cells. The expression of pro-apoptotic proteins such as caspase-3, caspase-9, and Bax were upregulated, while the expression level of apoptotic Bcl-2 was significantly down-regulated. Moreover, NC reduced SOD activity and MDA content in CC cells. In addition, studies on pathway phosphorylation have shown that NC inhibits the expression of p-erk and p-akt proteins. Finally, the results were further confirmed by experiments in nude mice. NC inhibited tumor growth in mice. NC promoted apoptosis in tissues. NC inhibited the expression of Ki67 and OCT4 in tissues. NC inhibited the phosphorylation of pathway proteins ERK1/2 and AKT in tissues.

Conclusions: NC treatment inhibited the proliferation and stemness of CC tissues, promoted the apoptosis of tumor tissues, downregulated the expression of p-ERK and p-AKT in tumor tissues, which suggests that NC may play an important role in regulating ERK and AKT pathways.

Keywords: Nitidine chloride (NC); cancer stem-like properties; mitochondrial membrane potential; colon cancer (CC)

Submitted Mar 26, 2020. Accepted for publication Apr 28, 2020.

doi: $10.21037 / \mathrm{atm}-20-3432$

View this article at: http://dx.doi.org/10.21037/atm-20-3432 


\section{Introduction}

Colon cancer (CC) is one of the most common malignant diseases in the world, with about 1.2 million people diagnosed with CC and more than 0.6 million people dying from the disease each year $(1,2)$. At present, surgery (3), adjuvant radiotherapy (4), adjuvant chemotherapy (5) and targeted therapy (6) are the main treatment methods for CC. However, although some progress has been made in the early diagnosis and treatment of $\mathrm{CC}$, many patients are not suitable for surgery, and the side effects of radiotherapy, chemotherapy and targeted therapy can be grievous (7). Therefore, new drugs are needed to improve 1 the effectiveness of existing treatments.

Natural products are attracting more and more attention as anti-tumor drugs because of their low tissue toxicity and wide range of biological activities (8). Nitidine chloride (NC) is a natural bioactive phytochemical alkaloid with antifungal, anti-inflammatory, and antioxidant effects (9-11). Previous studies have shown that NC can inhibit cancer in a variety of human cancers (12). Shi et al. reported that NC inhibited cell proliferation and invasion by downregulating the expression of YAP in prostate cancer cells (13). In vivo studies have shown that NC acts on checkpoint kinase 2 to promote the apoptosis of cervical cancer cells (14). $\mathrm{Ou}$ et al. confirmed that NC induced apoptosis of human liver cancer cells through p53, p21, Bax, bcl-2, and other pathways (15). In ovarian cancer, NC and adriamycin were shown to be able to synergistically block cell proliferation and promote cell apoptosis (16). Other studies have shown that NC suppresses the cell growth of CC and promotes apoptosis through the ERK pathway. However, the effect of $\mathrm{NC}$ on colorectal cancer has been rarely reported. In the present investigation, we focused on how NC affects cancer stem cell-like characteristics and mitochondrial membrane potential of CC SW480 cells.

We present the following article in accordance with the ARRIVE reporting checklist (available at http://dx.doi. org/10.21037/atm-20-3432).

\section{Methods}

\section{Cell culture}

Human CC SW480 cells were purchased from China Procell Inc. The cell line SW480 is derived from human colon adenocarcinoma in situ. SW480 cells were added to Dulbecco's Modified Eagle Medium (DMEM) (Gibco, USA) containing $10 \%$ fetal bovine serum (FBS) and cultured at $5 \% \mathrm{CO}_{2}$ at $37{ }^{\circ} \mathrm{C}$. $\mathrm{NC}$ (purity >98\%) was purchased from Xianxin Biochemical Technology (Sichuan, China). In this study, three concentrations with times ratio $(0.25,0.5,1 \mu \mathrm{M})$ were selected from 0.1 to $1 \mu \mathrm{M}$; three concentrations with times ratio $(2.5,5,10 \mu \mathrm{M})$ from 1 to $10 \mu \mathrm{M}$; three concentrations with times ratio $(25,50$, $100 \mu \mathrm{M})$ from 10 to $100 \mu \mathrm{M}$, and one concentration $(200 \mu \mathrm{M})$ from 100 to $200 \mu \mathrm{M}$. Different concentrations of NC $(0$, $0.25,0.5,1,2.5,5,10,25,50,100$, and $200 \mu \mathrm{M})$ were added to the cell-containing medium and cultured for 24 hours.

\section{Cell viability}

The viability of SW480 cells after NC treatment was analyzed using a CCK-8 assay (CA1210, Solarbio, Beijing, China). The cells were inoculated in 96-well plat at a density of 1,500 cells/well and treated with $\mathrm{NC}(0,0.25$, $1,2.5,5,10,25,50,100,200 \mu M)$ for $24 \mathrm{~h}$. Subsequently, the cells were incubated overnight in an incubator at $37^{\circ} \mathrm{C}$ and $5 \% \mathrm{CO}_{2} .10 \mu \mathrm{L}$ CCK-8 solution was added to each well and cultured for 2 hours under the same conditions. The absorbance of each well at $450 \mathrm{~nm}$ was measured by a multifunctional microplate reader SuPerMax 3100 (M Shanpu, China).

\section{EdU assay}

SW480 cells from the exponential growth period were inoculated on 96-well plates. Four kinds of concentrations of $\mathrm{NC}(0,2.5,5,10 \mu \mathrm{M})$ were added to the cell-containing medium and cultured for $24 \mathrm{~h}$. The concentration of ClickiT EdU (Thermo Fisher, USA) was adjusted to $20 \mu \mathrm{M}$ with DMEM (Gibco, USA). After $2 \mathrm{~h}$ of cell culture, the cells were fixed with $4 \%$ paraformaldehyde for $0.5 \mathrm{~h}$, stained overnight with Alexa Fluor 594 (Abcam, UK), and observed with a fluorescence microscope (Olympus, Japan). Results were analyzed by image-pro Plus 6.0 software (Media Cybernetics Inc., USA). The experiments were repeated 3 times.

\section{Sphere formation assay}

SW480 cells from the exponential growth period were inoculated on 96-well plates. Four kinds of concentrations of $\mathrm{NC}(0,2.5,5,10 \mu \mathrm{M})$ were added to the cell-containing medium and cultured for $24 \mathrm{~h}$. After counting the cells, the cells were spread in a Nunclon ${ }^{\mathrm{TM}}$ Sphera ${ }^{\mathrm{TM}}$ petri dish (Thermo Fisher, USA) at a density of $2 \times 10^{5}$ cells per dish. 
Serum-free DMEM (Gibco, USA) containing epidermal growth factor (EGF) (Sigma, USA), $20 \mathrm{ng} / \mathrm{mL}$ basic fibroblast growth factor (b-FBF, Invitorgen, USA) and 2\% B27 (Invitorgen, USA) were added. Half of the old medium was removed and replaced every 7 days.

\section{Flow cytometry analysis}

SW480 cells from the exponential growth period were inoculated on 96-well plates. Four kinds of concentrations of $\mathrm{NC}(0,2.5,5,10 \mu \mathrm{M})$ were added to the cell-containing medium and cultured for 24 hours. Trypsin was used to digest the cultured cells, and the cells were washed with phosphate-buffered saline (PBS) 3 times before resuspension. Then, anti-cd44-pe, anti-cd133-fitc and their respective isotype controls were added and incubated at room temperature for $40 \mathrm{~min}$. The cells were then washed with PBS and resuspended. An FSC vs. SSC dot map was created in the flow cytometry (BD, USA). The gate control is in the FSC-low area in group 0uM. The cell ratios of $\mathrm{CD} 44^{+}$and $\mathrm{CD} 133^{+}$were analyzed by the flow cytometry.

The fluorescent probe JC-1 is a cationic lipophilic dye, which can cross the cell membrane freely and maintain a dynamic equilibrium on both sides of the membrane with the change of the cell membrane potential. In this experiment, $1 \times 10^{6} \mathrm{SW} 480$ cells treated with $\mathrm{NC}$ were resuspended in $1 \mathrm{~mL}$ culture medium after trypsinization, and incubated with $10 \mu \mathrm{g} / \mathrm{mL} \mathrm{JC}-1$ at $37{ }^{\circ} \mathrm{C}$ for $30 \mathrm{~min}$ under the condition of $5 \% \mathrm{CO}_{2}$. After staining with JC-1, all cells were set as positive in the FL1 channel in flow cytometry using gate control in group $0 \mu \mathrm{M}$. Then, red and green emission fluorescence was analyzed.

\section{The content of SOD and MDA was detected by the kit}

Follow the instructions of SOD or MDA kit manufacturer for the operation. The cells were collected into the centrifuge tube, and the supernatant was discarded after centrifugation. At the rate of $1 \mathrm{~mL}$ extraction solution per 4 million cells, the cells were broken by ultrasound (power 20\%, ultrasound $3 \mathrm{sec}$, interval $10 \mathrm{sec}$, repeat 30 times). Centrifuge at $8,000 \mathrm{~g}$ at $4{ }^{\circ} \mathrm{C}$ for $10 \mathrm{~min}$, take the supernatant and place it on ice. Absorbance was determined at $450 \mathrm{~nm}$.

\section{Western blotting (WB) assay}

SW480 cells from the exponential growth period were inoculated on 96-well plates. Four kinds of concentrations of $\mathrm{NC}(0,2.5,5,10 \mu \mathrm{M})$ were added to the cell-containing medium and cultured for $24 \mathrm{~h}$. Trypsin was used to digest the cultured cells. The total proteins of SW480 cells were isolated by sodium dodecyl sulfate-polyacrylamide gel electrophoresis (SDS-PAGE) (Solarbio, China) and transferred to the polyvinylidene fluoride (PVDF) membrane (Solarbio, China). After sealing with the blocking solution, the first antibody (Ki67, PCNA, NANOG, SOX2, OCT4, Bax, Caspase-3, Caspase-9, ERKk1/2, p-ERK1/2, AKT, p-AKT, STAT3, p-STAT 3, P65, p-P65, and actin) (CST, USA) was added to the membrane and incubated overnight at $4^{\circ} \mathrm{C}$. Then, the cells were washed with PBS and incubated with sheep anti-rabbit IgG-horseradish peroxidase (HRP) (Solarbio, China) for $1 \mathrm{~h}$. The strips were colored with enhanced chemiluminescent (ECL) kits (Solarbio, China).

\section{Terminal deoxynucleotidyl transferase dUTP nick end labeling (TUNEL) assay}

To detect apoptosis in paraffin sections, terminal deoxynucleotidyl transferase dUTP nick end labeling (TUNEL) assay kit was used (Biyuntian, China). Following the reagent manufacturer's instructions, each section was observed under an optical microscope, and images were obtained. Apoptotic cells were counted at a random magnification of five fields in each slice.

\section{Immunobistochemistry}

First, the paraffin section was dewaxed. Then $5 \%$ of the normal goat serum blocking non-specific protein was added, followed by the first antibody (Ki67, OCT4) (CST, USA), and co-incubated at $4{ }^{\circ} \mathrm{C}$ for $1 \mathrm{~h}$. After washing with tris-buffered saline with Tween20 (TBST), the SignalStain ${ }^{\circledR}$ Boost IHC Detection Reagent (CST, USA) was added, and incubated at room temperature for $30 \mathrm{~min}$. Then, SignalStain DAB Substrate Kit (CST, USA) was used for color rendering. The section was observed under an optical microscope (Olympus, Japan).

\section{Animal models}

Twenty male adult BALB/c nude mice (with a starting body weight of 20-22 g, SPF) were purchased from Nanjing Junke Biological Engineering Co., Ltd. The mice were kept under pathogen-free conditions with controlled temperature 
$\left(22{ }^{\circ} \mathrm{C}\right), 60 \%$ per cent humidity, and a 12 -hour light/dark cycle. All animal treatments were performed strictly in accordance with international ethical guidelines and the National Institutes of Health Guide concerning the Care and Use of Laboratory Animals. All animal experiments have been approved by the Yantaishan Hospital's animal care and use committee.

SW480 cells $\left(5 \times 10^{6}\right)$ were inoculated by subcutaneous (s.c.) injection into the flanks of the mice. According to previous reports (17), 5 days after successful modeling, nude mice were randomly divided into a quality control group (NC $0 \mathrm{M}$ ) and a test group (NC $4.5 \mathrm{mg} / \mathrm{kg}$ ), with 10 mice in each group, 6 days a week. The body weight of the nude mice was measured every 3 days until day 30 . Tumor size was determined by measuring the major $(\mathrm{L})$ and minor $(\mathrm{W})$ diameter with a caliper. After 30 days, mice were euthanized by intraperitoneal injection of pentobarbital sodium ( $200 \mathrm{mg} / \mathrm{kg}$ body weight). The tumor weight was measured. Tumors were harvested for subsequent experiments.

\section{Statistical analysis}

GraphPad Prism 7.0 software was used for statistical analysis. The results were expressed as mean $\pm \mathrm{SD}$. The experiments were carried out in triplicate. The two groups were compared using the $t$ test. Multi-group comparison was performed by one-way analysis of variance. $\mathrm{P}<0.05$ was considered statistically significant.

\section{Results}

\section{NC inbibited the proliferation of SW480 cells}

In this study, CCK-8 assay was performed to detect the viability of CC SW480 cell lines treated with $\mathrm{NC}$ at different concentrations, and 4 doses without significant toxicity were selected: $0,2.5,5$, and $10 \mu \mathrm{M} \mathrm{NC}$ for subsequent experiments (Figure 1A). Cell proliferation was measured using an EdU assay. The results showed that the proliferation of SW480 cells was inhibited by NC, and the ability to inhibit cell proliferation was stronger with the increase of NC concentration (Figure 1B). Meanwhile, proliferation-related Ki67 and proliferating cell nuclear antigen (PNCA) proteins were detected by WB analysis. Experimental data showed that NC inhibited the expression levels of Ki67 and PNCA in SW480 cells, and the expression level decreased with the increase of $\mathrm{NC}$ concentration (Figure 1C). These tests showed that $\mathrm{NC}$ inhibited the growth of SW480 cells.

\section{NC inbibited tumor stemness in SW480 cells}

Under the microscope, tumor sphere formation in SW480 cells appeared very obvious, but in the SW480 cells containing NC, tumor pellet formation was clearly obstructed. In NC-treated SW480 cells, both sphere diameter and sphere number decreased significantly, and decreased more significantly with the increase of $\mathrm{NC}$ dose (Figure 2A). Subsequently, WB was used to detect the expression levels of proteins associated with stem cell properties, including NANOG, SOX2, and OCT4. Experimental data showed that NC greatly suppressed the expression of NANOG, SOX2 and OCT4, and the higher the concentration of $\mathrm{NC}$, the better the inhibitory effect (Figure 2B). Furthermore, the number of tumor stem cell markers for $\mathrm{CD} 133^{+}$or $\mathrm{CD} 44^{+}$cells was detected by flow cytometry. The number of $\mathrm{CD} 133^{+}$or $\mathrm{CD} 44^{+}$cells decreased significantly in NC-treated SW480 cells, and the greater the concentration of $\mathrm{NC}$, the more significant the decrease (Figure 2C). These experiments all confirmed that $\mathrm{NC}$ weakened the stem cell properties of SW480 cells.

\section{NC changed the mitochondrial membrane potential and promoted the apoptosis of SW480 cells}

A large number of studies have shown that mitochondria are closely linked to cell apoptosis, among which the change of mitochondrial transmembrane potential is considered to be one of the earliest processes in the cascade of cell apoptosis. The activity of JC-1 detected by flow cytometry showed that the red-green percentage value of JC-1 decreased gradually with the increase of $\mathrm{NC}$ concentration, confirming that $\mathrm{NC}$ changed the mitochondrial membrane potential and led to the apoptosis of SW480 cells (Figure $3 A$ ). In addition, WB detected apoptosis-related proteins Bax, Bcl-2, Caspase-3, and Caspase-9. The data showed that the expressions of Bax, Bcl-2, caspase- 3 and caspase- 9 were up-regulated by NC (Figure 3B). Furthermore, SOD activity and MDA content related to apoptosis were detected. The results demonstrated that SOD activity decreased significantly in NC-treated SW480 cells, while MDA content increased significantly (Figure 3C). The above experiments showed that $\mathrm{NC}$ accelerated the process of cell apoptosis. 
A

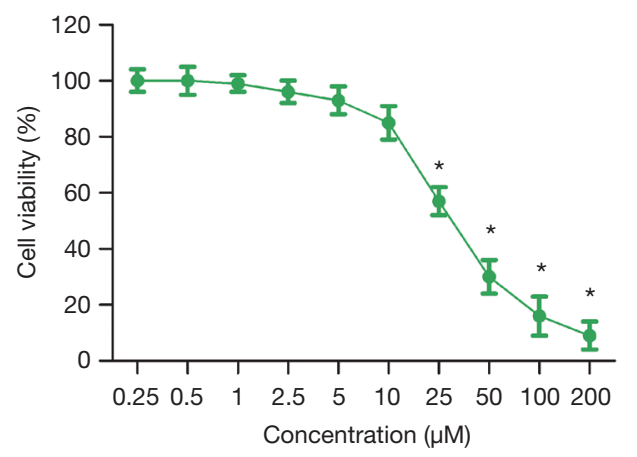

B

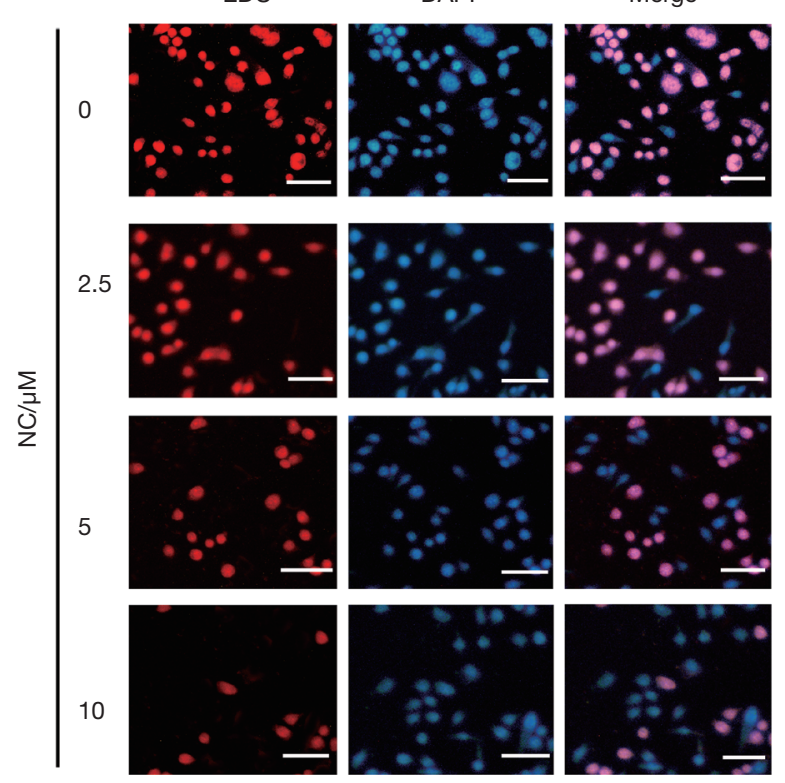

C

C
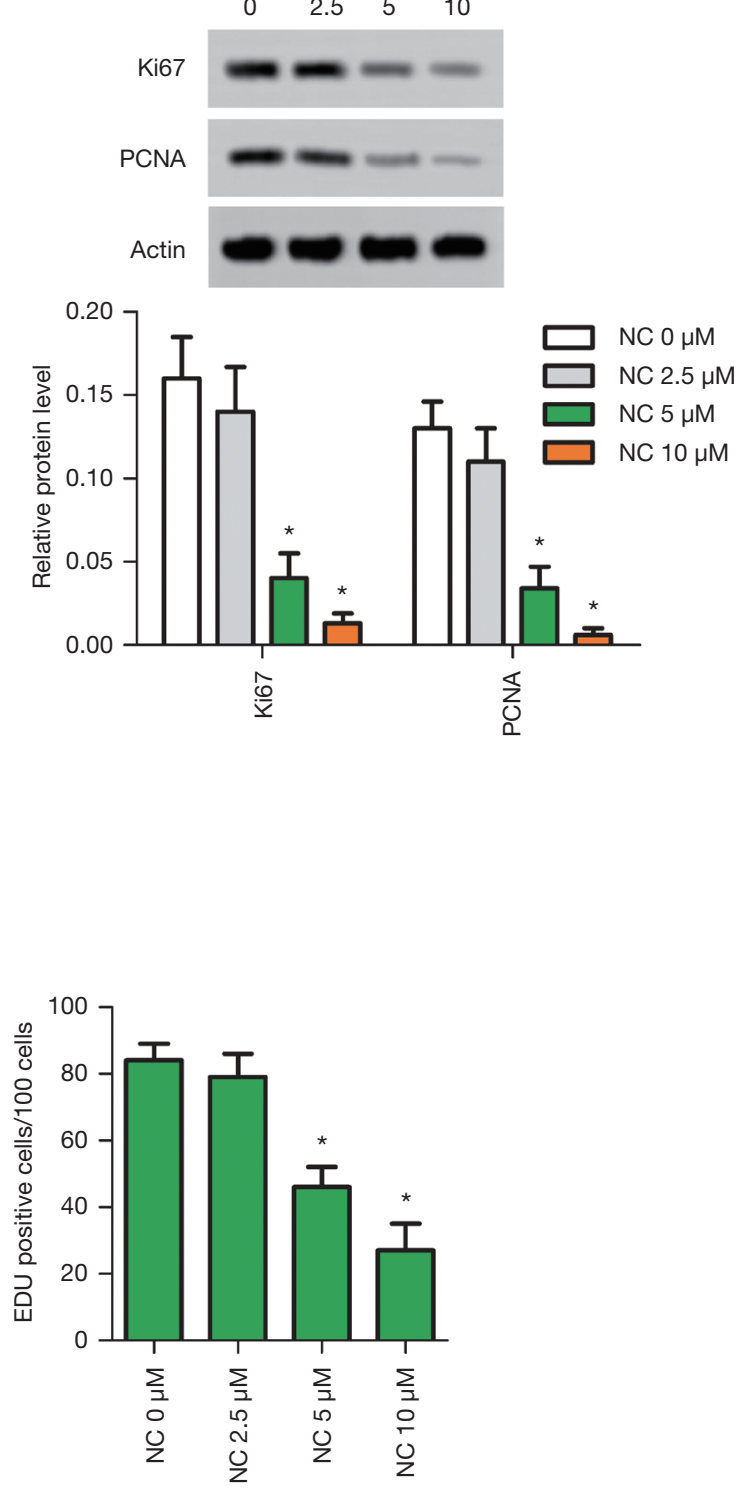

Figure 1 Effect of NC on cell viability and proliferation in colon cancer SW480 cells. (A) SW480 cells were treated with NC at various dosages $(0,0.25,0.5,2.5,5,10,25,50,100$, and $200 \mu \mathrm{M})$ for $24 \mathrm{~h}$; cell vitality was measured using a CCK-8 assay; (B) EdU staining was used to detect the proliferation of SW480 cells (scale bar $=50 \mu \mathrm{m}$ ); (C) Western blotting was conducted to detect the expression of proliferationrelated proteins Ki67 and PNCA. The experiments were repeated 3 times, and the data are shown as means $\pm \mathrm{SD} .{ }^{*}, \mathrm{P}<0.05 v s . \mathrm{NC} 0 \mu \mathrm{M}$ group. NC, nitidine chloride.

\section{NC downregulated the phosphorylation of key pathway proteins in SW480 cells}

In the present study, phosphorylation of key proteins in related pathways was also investigated. P-ERK1/2 and p-AKT expression were significantly downregulated in NC- treated SW480 cells (Figure 4A). However, the expression of STAT3 and p-65 did not change significantly (Figure 4B). The above experiments showed that NC inhibited the phosphorylation expression of AKT and ERK, indicating that $\mathrm{NC}$ regulated the signaling pathways involved in AKT and ERK. 
A

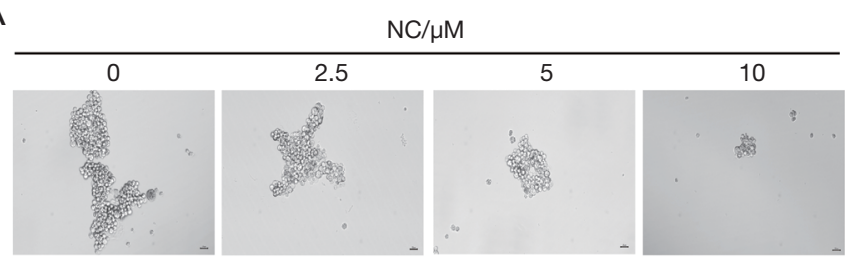

\section{B}

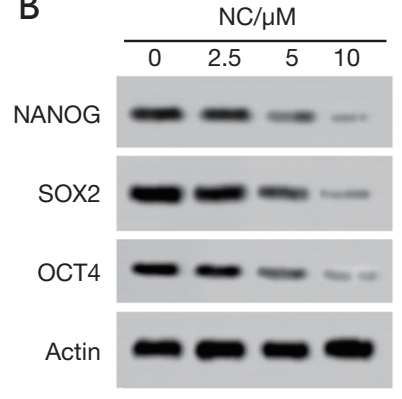

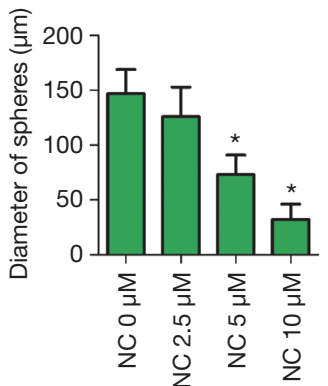

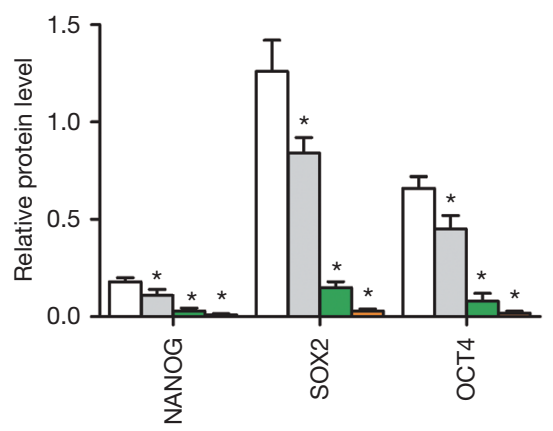

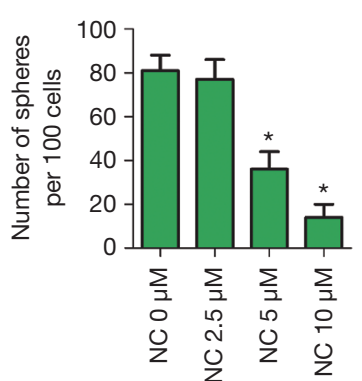
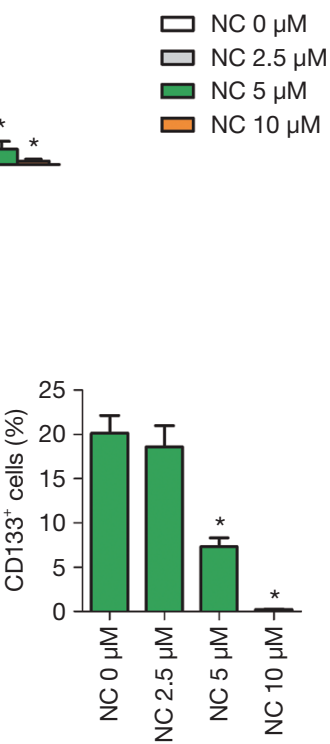

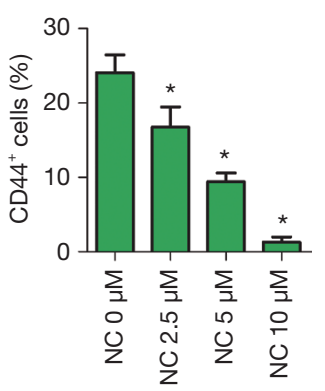

Figure 2 Effects of NC on stem cell characteristics of SW480 cells. (A) Sphere formation assay of SW480 cells (scale bar =50 $\mu$ m); (B) Western blotting was used to detect NANOG, SOX2, and OCT4 proteins related to stem cell properties in SW480 cells; (C) the number of stem cell markers CD133 and CD44 positive cells was determined by flow cytometry. The assays were repeated 3 times, and the data are shown as means $\pm \mathrm{SD}$. * $\mathrm{P}<0.05$ vs. $\mathrm{NC} 0 \mu \mathrm{M}$ group. $\mathrm{NC}$, nitidine chloride.

\section{NC suppressed the growth of tumor tissue in vivo}

In this study, SW480 cells were subcutaneously injected into mice to construct a transplanted tumor model. According to previous studies, the dose of $\mathrm{NC}$ in the experimental group was $4.5 \mathrm{mg} / \mathrm{kg}$. The tumor weight of the experimental group was much smaller than that of the control group (Figure $5 A, B$ ). Adverse reactions to NC were determined by changes in body weight of the mice.

During the experiment, $\mathrm{NC}$ had no effect on the body weight of mice (Figure 5C). TUNEL and Immunohistochemistry (IHC) were performed to detect the expression of proteins related to apoptosis, proliferation, and stem cell characteristics of in vivo tissues. TUNEL results showed that apoptotic cells increased significantly in the NC group. IHC results showed that Ki67 and OCT4 expressions were significantly decreased in the NC treatment (Figure 5D). Moreover, the results of WB showed that the expression levels of p-ERK1/2 and p-AKT in the NC group were significantly down-regulated in tumor tissues, which was consistent with the results of the in vitro experiments (Figure 5E). In addition, the activity of SOD in the tumor model showed that the activity of SOD in the $\mathrm{NC}$ group was significantly lower than that in the control group (Figure $5 F$ ). The above experiments collectively 
A
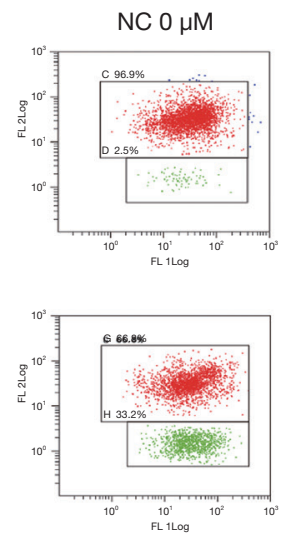

$\mathrm{NC} 5 \mu \mathrm{M}$
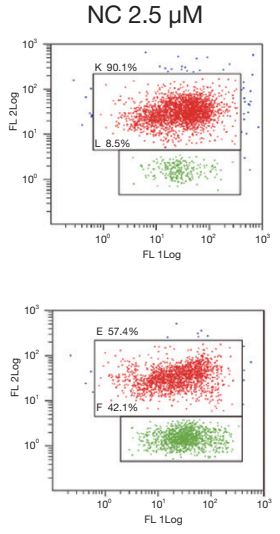

$\mathrm{NC} 10 \mu \mathrm{M}$

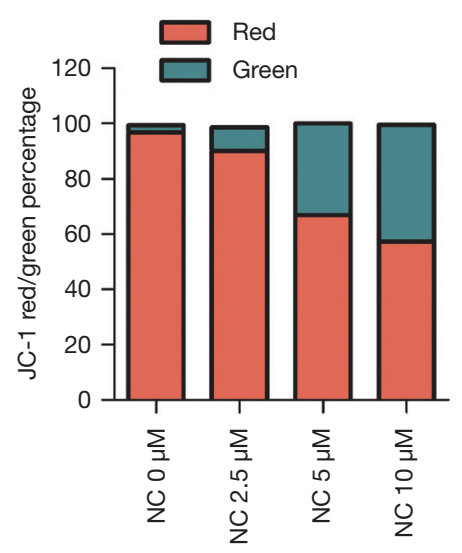

B
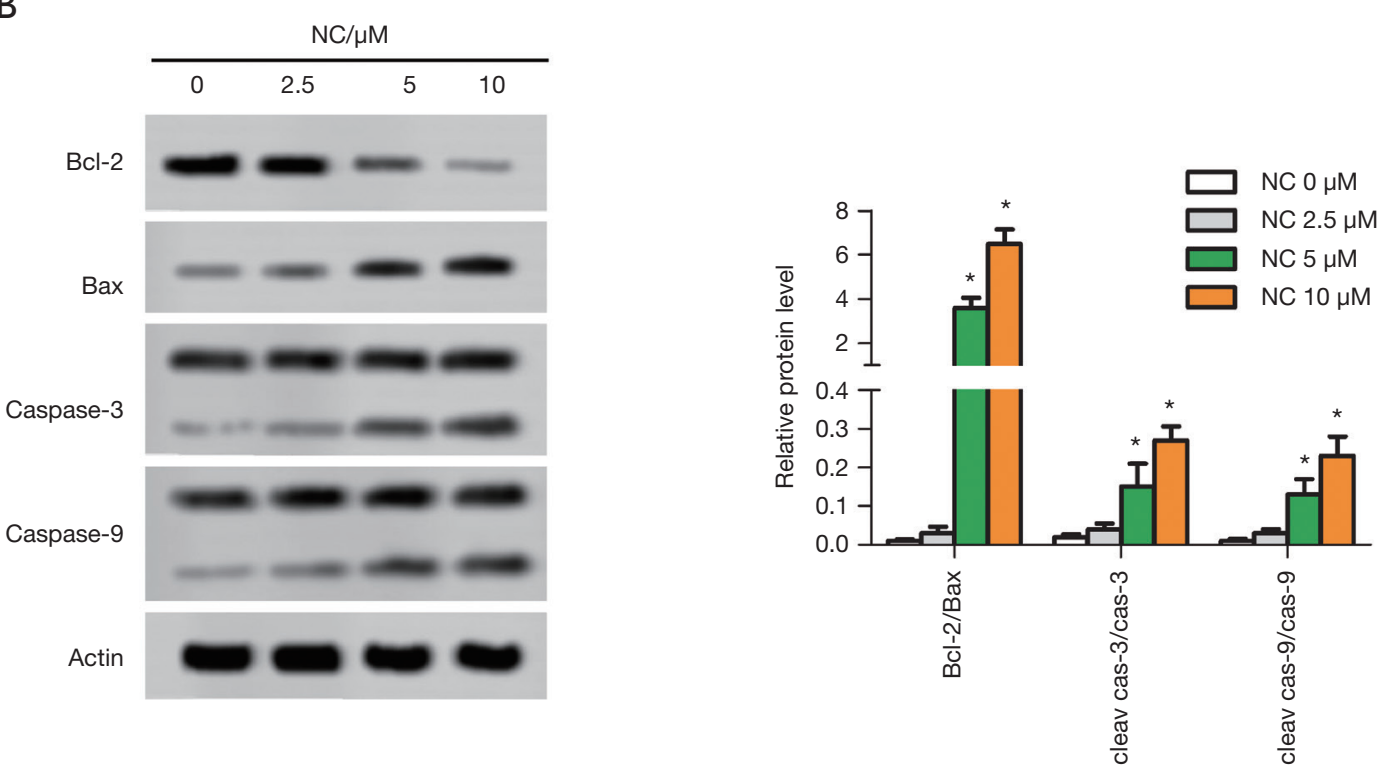

C
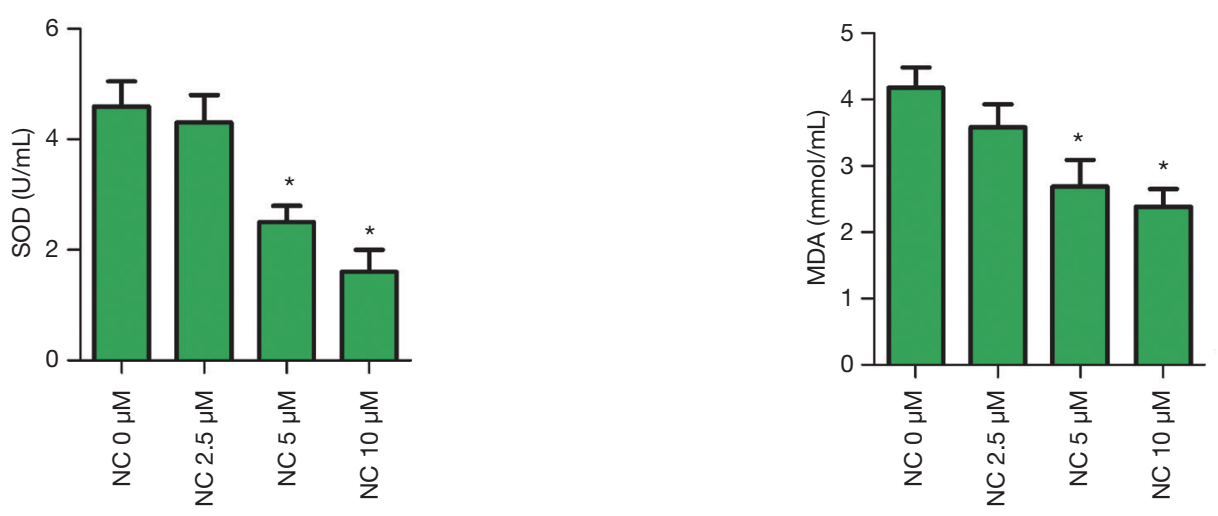

Figure 3 Effects of NC on mitochondrial membrane potential and apoptosis of SW480 cells. (A) The red-green percentage of mitochondrial JC-1 activity was determined by flow cytometry; (B) expression of apoptosis-related proteins Bcl-2, Bax, Caspase-3, and Caspase-9 in SW480 cells was detected by Western blotting; (C) SOD activity and MDA content were detected in SW480 cells. The experiments were repeated 3 times, and the data are shown as means $\pm \mathrm{SD}$. *, $\mathrm{P}<0.05 v s$. NC $0 \mu \mathrm{M}$ group. $\mathrm{NC}$, nitidine chloride. 

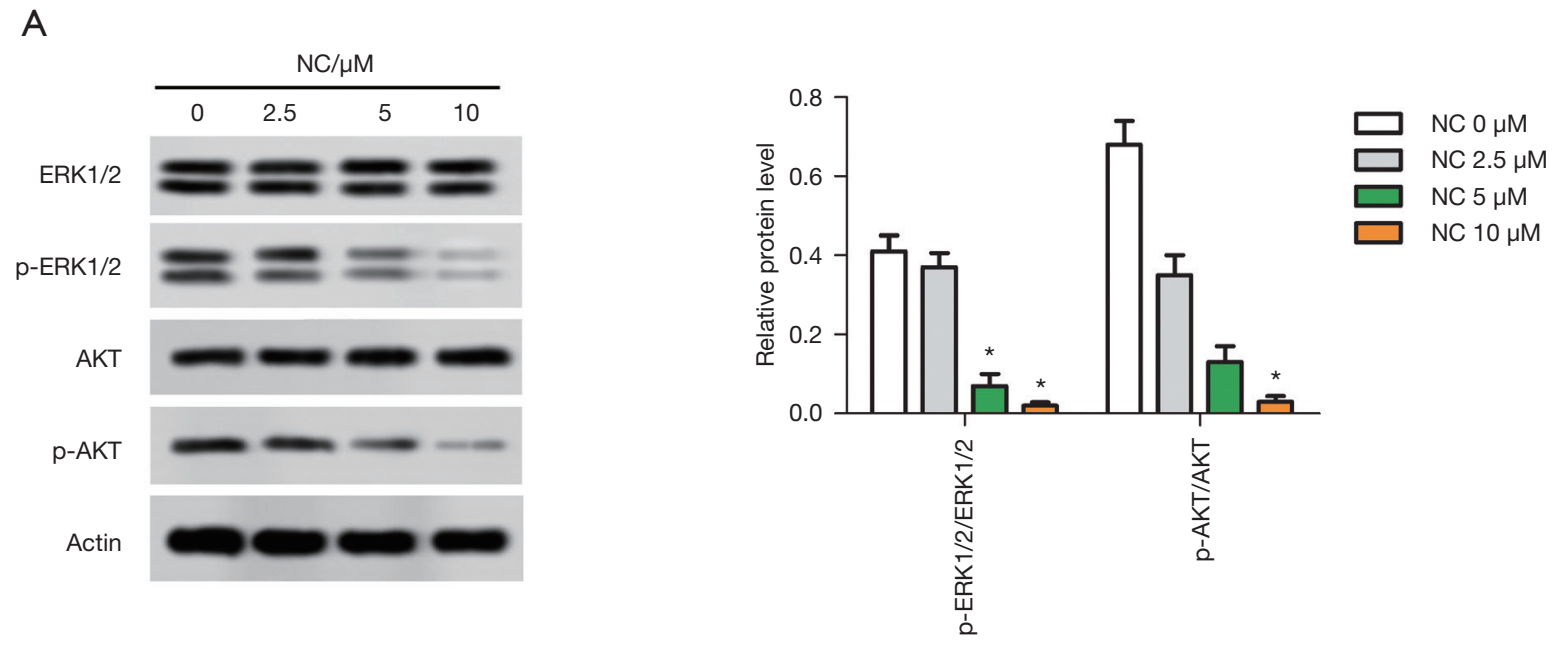

B
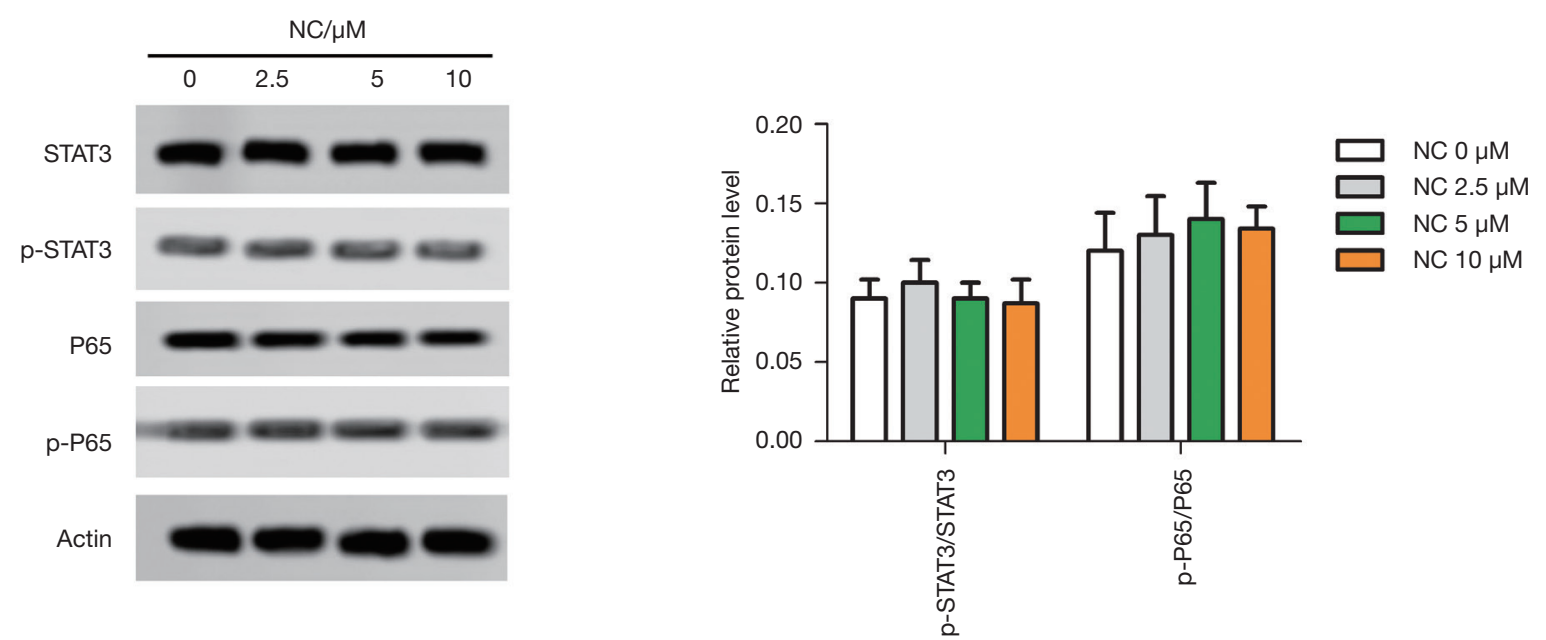

Figure 4 Effects of NC on phosphorylation of key proteins in related pathways. (A) The expression of ERK1/2, p-ERK1/2, AKT, and p-AKT was detected by Western blotting; (B) the expression of erk1/2, p-erk1/2, AKT, and p-AKT was detected by Western blotting. The assays were repeated 3 times, and the data are shown as means \pm SD. * $\mathrm{P}<0.05$ vs. NC $0 \mu M$ group. NC, nitidine chloride.

demonstrate that $\mathrm{NC}$ can inhibit the proliferation of stem cell characteristics and accelerate the apoptosis of tumor tissues in vivo.

\section{Discussion}

The unrestricted proliferation and resistance to apoptosis of tumor cells provide a survival advantage against conventional chemotherapy drugs (18). NC, as a kind of plant extract treatment, has attracted increasing attention due to its pleiotropic anticancer effect in inhibiting tumor angiogenesis, proliferation, and metastasis in a variety of cancers (19-21). Some reports have confirmed the inhibitory effect of NC on the proliferation of hepatocellular carcinoma cells (17). Other studies have shown that NC inhibits the proliferation of nasopharyngeal carcinoma cells through p53 upregulation (22). In this study, we also found that NC inhibited the proliferation of CC SW480 cells at the cellular level. In the same way, NC blocked the expression of Ki67 and PNCA at the protein level. The proliferation activity of tumor cells is an important prognostic index in tumor diagnosis.

Colorectal cancer (CC) is one of the most common malignant tumors in the world (23). Many studies support 
A

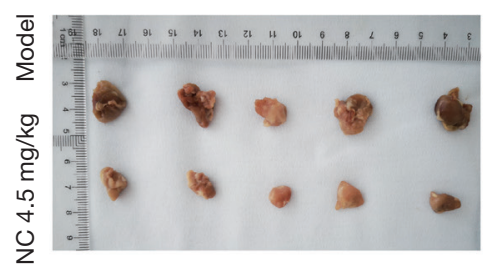

D

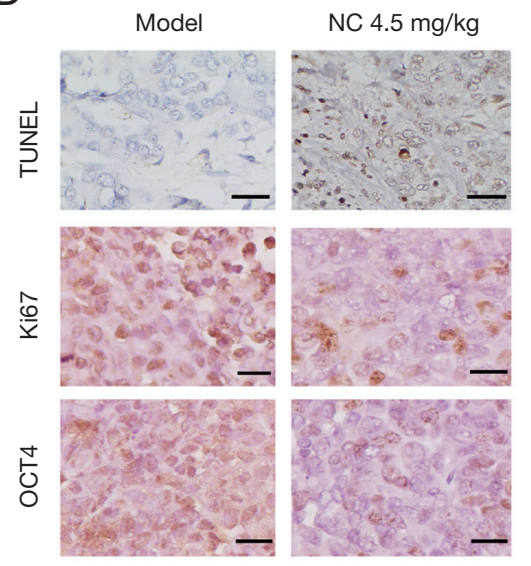

E

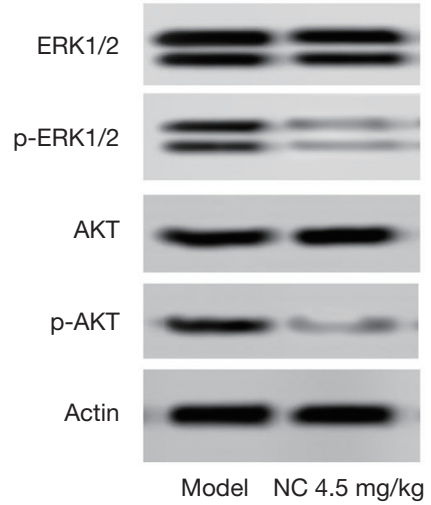

B

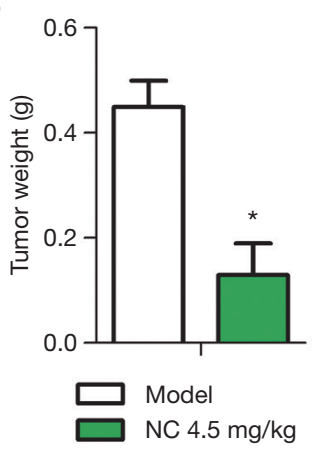

C

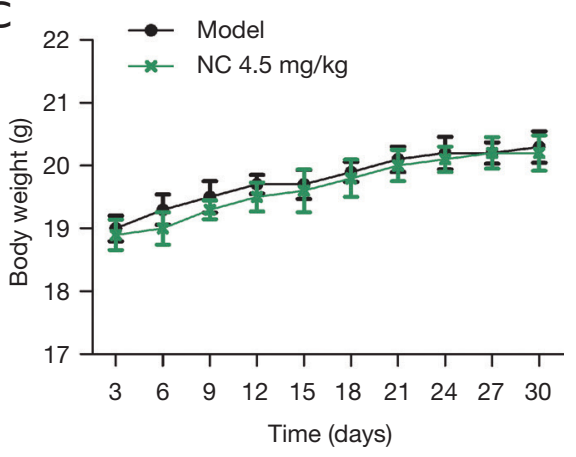

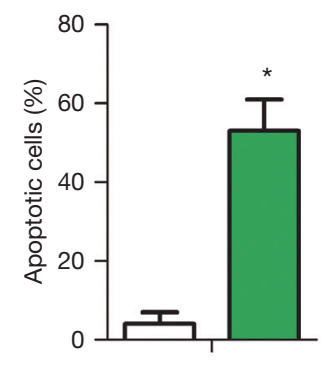

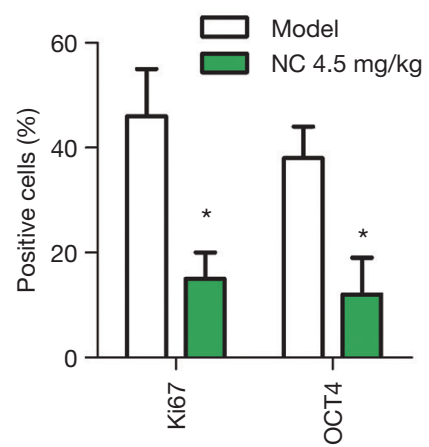

$\mathrm{F}$
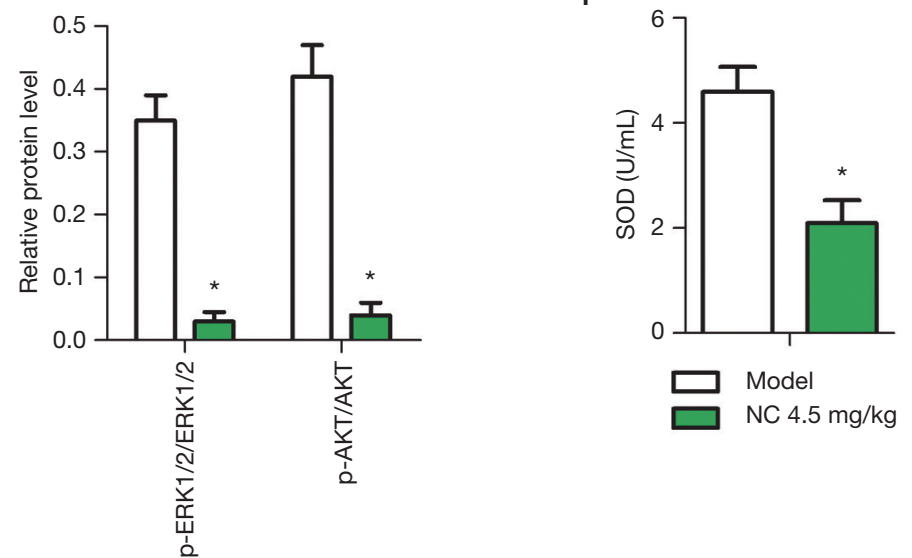

Figure 5 Effects of $\mathrm{NC}$ on colon cancer tumor tissue in vivo. (A) Representative images for tumors; (B) tumor weight; (C) body weight of the model nude mice; (D) the number of apoptotic cells was detected by TUNEL, and IHC was used to detect proliferation-related Ki-67 and stem cell-specific OCT4 expression in vivo (scale bar $=50 \mu \mathrm{m}$ ); (E) phosphorylation of ERK1/2 and AKT in vivo was detected by Western blotting; (F) determination of SOD activity in vivo. The experiments were repeated 3 times, and the data are shown as means \pm SD. *, $\mathrm{P}<0.05$ vs. NC $0 \mu \mathrm{M}$ group. NC, nitidine chloride. 
the concept of cancer stem cells (CSCs) playing a central role in the development of cancer. CSCs have been the focus of research in a series of cancers, including CC (24). CSCs have the property of self-renewal, and they are often uncontrolled during tumorigenesis. Many cultured CSC lines formed free-floating spherical living cell clusters, which CSC dominated $(25,26)$. In our study, NC-treated CC cells demonstrated the ability to inhibit the formation of tumor spheres. Multiple genes including CD44 and CD133 were expressed in CC CSCs $(27,28)$. Nanog, SOX2, and OCT4 co-occupy and regulate their own promoters and other developmental genes with multiple functions, and they work together to form a broad regulatory circuit, including the automatic regulatory circuit and the feedforward circuit (29). This study showed that NC reduced the number of $\mathrm{CD} 44^{+}$and $\mathrm{CD} 133^{+}$subsets and inhibited the expression of NANOG, OCT4, and SOX2 in SW480 cells. These results suggest that CC cells may lose CSC-like characteristics after NC treatment.

Mitochondria are productive organelles and mitochondrialdependent pathway is the most common apoptosis pathway in vertebrate cells (30). Mitochondrial membrane permeability (MOMP) is a key step in inducing apoptosis. Mitochondrial membrane depolarization causes the release of apoptogenic factors (such as cytochrome c), which are involved in caspase-dependent apoptosis $(31,32)$. Bcl-2 family members are crucial regulators of apoptosis induced by mitochondrial membrane permeability (MOMP), including Bcl-2 which suppresses apoptosis, and Bax which promotes apoptosis (33). Bax protein forms pores in the mitochondria, leading to changes in mitochondrial membrane potential gradient, and these pores are inhibited by Bcl-2 protein (34). Therefore, the proportion of antiapoptotic and pro-apoptotic Bcl-2 family members determines the fate of cells, and the abnormal expression of these proteins alters this proportion, disrupting the normal apoptotic process and leading to a variety of apoptosisrelated diseases, including cancer (35). Mitochondrialdependent pathways lead to further activation of caspase- 9 and the downstream effector protein caspase-3 (36). In present study, $\mathrm{NC}$ reduced the membrane potential ratio of mitochondria JC-1, while Bax/Bcl-2, caspase-3, and caspase- 9 were upregulated. These results all confirmed that NC promoted apoptosis by changing the permeability of mitochondrial membrane. It has been reported that SOD activity and MDA concentration in colorectal cancer tissues are higher than those in normal tissues $(37,38)$. In this investigation, we found that NC inhibited SOD activity and
MDA level in SW480 cells.

Mitogen-activated protein kinase (MAPK) pathway is composed of 3-layer kinase modules, in which MAPK is phosphorylated and activated by mitogen-activated protein kinase kinase (MAPKK), and MAPKK is phosphorylated and activated by mitogen-activated protein kinase kinase kinase (MAPKKK) in turn. The MAPK pathway links extracellular signals to mechanisms that control basic cellular activity (39). ERK pathway is the best studied MAPK pathway in mammals, and is involved in modulating the proliferation, differentiation, senescence, and apoptosis of cancer cells (40). AKT interacts with phospholipid inositol, causing its transport to the intima, where it is phosphorylated and activated by PDK1 and PDK2. Activated AKT regulates the function of a variety of substrates involved in regulating cell survival, cell cycle progression, and cell growth (41). In recent years, studies have shown that multiple receptor-induced survival signals are mainly mediated by PI3K/AKT, so this pathway may play a decisive role in the emergence of drug-resistant phenotypes after radiotherapy and chemotherapy for cancer (42). Previous studies have shown that NC blocks proliferation and metastasis of renal cancer cells and induces apoptosis by inhibiting the AKT and ERK signaling pathways $(20,43)$. In this study, we examined the phosphorylation of ERK1/2 and AKT pathways and found that NC downregulated the phosphorylation of ERK 1/2 and AKT in CC SW480 cells.

Signal transducers and transcriptional activators 3 (STAT-3) are 1 of the 6 members of the transcription factor family. STAT3 plays an important role in proliferation, cell survival, and angiogenesis (44). Receptor and nonreceptor protein tyrosine kinases phosphorylate tyrosine 705, which regulates stat3 activation. These kinases include epidermal growth factor receptor kinase (EGFR) (45), Src (46), Janus-activated kinase (JAK) (47), and extracellular signaling-regulated kinase (ERK) (48). Accumulative studies have reported that $\mathrm{NC}$ induces cell apoptosis and inhibits cell growth by inhibiting STAT3 in ovarian and liver cancer $(49,50)$. In mammals, p 65 and p50 are the most abundant members of NF- $\mathrm{KB}$ transcription factors (51). I $\kappa \mathrm{B}$ s is phosphorylated by I $\kappa \mathrm{B}$ kinase, which is activated by ubiquitination and proteasomal degradation. This process transfers p65 into the nucleus and enables p65 to regulate the gene transcription process of cell survival, invasion, and metastasis (52). NF-kB is increasingly considered to play a key role in many cancers (53). It has been reported that both wild-type and active p 65 can be overexpressed in 
the presence of activated AKT, suggesting that p65 plays a key role in promoting the development of prostate cancer tumors (51). However, in this study, we found no significant changes in the phosphorylation of STAT3 and p65 in NCtreated SW480 cells, suggesting that NC may not regulate cells through the signaling pathways involved in STAT3 and $\mathrm{p} 65$.

In summary, our results suggest that $\mathrm{NC}$ inhibits the tumor stem cell-like characteristics and proliferation of CC cells, and depolarizes the mitochondrial membrane to promote apoptosis. In the study of phosphorylation of signaling pathways, $\mathrm{NC}$ was found to be involved in the regulation of ERK and AKT signaling pathways, leading to the downregulation of the phosphorylation levels of ERK and AKT. However, NC may not significantly change the phosphorylation levels of STAT3 and p65, suggesting that $\mathrm{NC}$ may not be involved in the STAT3 and p65 signaling pathways, but more comprehensive studies are needed to confirm this. These results were also validated in vivo. In conclusion, $\mathrm{NC}$ can affect multiple targets in CC cells and may be used as a new drug for the treatment of CC.

\section{Acknowledgments}

We would like to give our sincere gratitude to the reviewers for their constructive comments.

Funding: None.

\section{Footnote}

Reporting Checklist: The authors have completed the ARRIVE reporting checklist. Available at http://dx.doi. org/10.21037/atm-20-3432

Data Sharing Statement: Available at http://dx.doi. org/10.21037/atm-20-3432

Conflicts of Interest: All authors have completed the ICMJE uniform disclosure form (available at http://dx.doi. org/10.21037/atm-20-3432). The authors have no conflicts of interest to declare.

Ethical Statement: The authors are accountable for all aspects of the work in ensuring that questions related to the accuracy or integrity of any part of the work are appropriately investigated and resolved.

Open Access Statement: This is an Open Access article distributed in accordance with the Creative Commons Attribution-NonCommercial-NoDerivs 4.0 International License (CC BY-NC-ND 4.0), which permits the noncommercial replication and distribution of the article with the strict proviso that no changes or edits are made and the original work is properly cited (including links to both the formal publication through the relevant DOI and the license). See: https://creativecommons.org/licenses/by-nc-nd/4.0/.

\section{References}

1. Brenner H, Kloor M, Pox CP. Colorectal cancer. Lancet 2014;383:1490-502.

2. Torre LA, Bray F, Siegel RL, et al. Global cancer statistics, 2012. CA Cancer J Clin 2015;65:87-108.

3. Jorissen RN, Sakthianandeswaren A, Sieber OM. Immunoscore- - has it scored for colon cancer precision medicine? Ann Transl Med 2018;6:S23.

4. Mendenhall WM, Amos EH, Rout WR, et al. Adjuvant postoperative radiotherapy for colon carcinoma. Cancer 2004;101:1338-44.

5. Kannarkatt J, Joseph J, Kurniali PC, et al. Adjuvant Chemotherapy for Stage II Colon Cancer: A Clinical Dilemma. J Oncol Pract 2017;13:233-41.

6. Banerjee A, Pathak S, Subramanium VD, et al. Strategies for targeted drug delivery in treatment of colon cancer: current trends and future perspectives. Drug Discov Today 2017;22:1224-32.

7. Kaufmann-Molnàr I, Hofmann Checchini H, Fringer A. Chemotherapeutic side effects in colon cancer. A qualitative study from the point of view of those affected. Pflege 2019;32:129-36.

8. Gordaliza M. Natural products as leads to anticancer drugs. Clin Transl Oncol 2007;9:767-76.

9. Hu J, Zhang WD, Liu RH, et al. Benzophenanthridine Alkaloids from Zanthoxylum nitidum (Roxb.) DC, and Their Analgesic and Anti-Inflammatory Activities. Chem Biodivers 2006;3:990-5.

10. Del Poeta M, Chen SF, Von Hoff D, et al. Comparison of in vitro activities of camptothecin and nitidine derivatives against fungal and cancer cells. Antimicrob Agents Chemother 1999;43:2862-8.

11. Wang $Z$, Jiang $W$, Zhang $Z$, et al. Nitidine chloride inhibits LPS-induced inflammatory cytokines production via MAPK and NF-kappaB pathway in RAW 264.7 cells. J Ethnopharmacol 2012;144:145-50.

12. Cui Y, Wu L, Cao R, et al. Antitumor functions and mechanisms of nitidine chloride in human cancers. J 
Cancer 2020;11:1250-6.

13. Shi Y, Cao T, Sun Y, et al. Nitidine Chloride inhibits cell proliferation and invasion via downregulation of YAP expression in prostate cancer cells. Am J Transl Res 2019;11:709-20.

14. Kwon HJ, Kim LH, Ahn CH, et al. A new insight into the apoptotic effect of nitidine chloride targeting Checkpoint kinase 2 in human cervical cancer. J Clin Biochem Nutr 2019;65:193-202.

15. Ou X, Lu Y, Liao L, et al. Nitidine chloride induces apoptosis in human hepatocellular carcinoma cells through a pathway involving p53, p21, Bax and Bcl-2. Oncol Rep 2015;33:1264-74.

16. Ding F, Liu T, Yu N, et al. Nitidine chloride inhibits proliferation, induces apoptosis via the Akt pathway and exhibits a synergistic effect with doxorubicin in ovarian cancer cells. Mol Med Rep 2016;14:2853-9.

17. Lin J, Shen A, Chen H, et al. Nitidine chloride inhibits hepatic cancer growth via modulation of multiple signaling pathways. BMC Cancer 2014;14:729.

18. Adams JM, Cory S. The Bcl-2 apoptotic switch in cancer development and therapy. Oncogene 2007;26:1324-37.

19. Chen J, Wang J, Lin L, et al. Inhibition of STAT3 signaling pathway by nitidine chloride suppressed the angiogenesis and growth of human gastric cancer. Mol Cancer Ther 2012;11:277-87.

20. Fang Z, Tang Y, Jiao W, et al. Nitidine chloride induces apoptosis and inhibits tumor cell proliferation via suppressing ERK signaling pathway in renal cancer. Food Chem Toxicol 2014;66:210-6.

21. Pan X, Han H, Wang L, et al. Nitidine Chloride inhibits breast cancer cells migration and invasion by suppressing c-Src/FAK associated signaling pathway. Cancer Lett 2011;313:181-91.

22. Kang M, Ou H, Wang R, et al. The effect of nitidine chloride on the proliferation and apoptosis of nasopharyngeal carcinoma cells. J BUON 2014;19:130-6.

23. Jemal A, Bray F, Center MM, et al. Global cancer statistics. CA Cancer J Clin 2011;61:69-90.

24. Munro MJ, Wickremesekera SK, Peng L, et al. Cancer stem cells in colorectal cancer: a review. J Clin Pathol 2018;71:110-6.

25. Tokar EJ, Qu W, Liu J, et al. Arsenic-specific stem cell selection during malignant transformation. J Natl Cancer Inst 2010;102:638-49.

26. Tokar EJ, Diwan BA, Waalkes MP. Arsenic exposure transforms human epithelial stem/progenitor cells into a cancer stem-like phenotype. Environ Health Perspect
2010;118:108-15.

27. Du L, Wang H, He L, et al. CD44 is of Functional Importance for Colorectal Cancer Stem Cells. Clin Cancer Res 2008;14:6751-60.

28. Ren F, Sheng WQ, Du X. CD133: a cancer stem cells marker, is used in colorectal cancers. World J Gastroenterol 2013;19:2603-11.

29. Rodda DJ, Chew JL, Lim LH, et al. Transcriptional regulation of nanog by OCT4 and SOX2. J Biol Chem 2005;280:24731-7.

30. Martinou JC, Youle RJ. Mitochondria in apoptosis: Bcl2 family members and mitochondrial dynamics. Dev Cell 2011;21:92-101.

31. Kroemer G, Galluzzi L, Brenner C. Mitochondrial Membrane Permeabilization in Cell Death. Physiol Rev 2007;87:99-163.

32. Vaux DL. Apoptogenic factors released from mitochondria. Biochim Biophys Acta 2011;1813:546-50.

33. Schinzel A, Kaufmann T, Borner C. Bcl-2 family members: integrators of survival and death signals in physiology and pathology [corrected]. Biochim Biophys Acta 2004;1644:95-105.

34. Wang C, Youle RJ. The role of mitochondria in apoptosis. Annu Rev Genet 2009;43:95-118.

35. Yip KW, Reed JC. Bcl-2 family proteins and cancer. Oncogene 2008;27:6398-406.

36. Zhou M, Liu X, Li Z, et al. Caspase-3 regulates the migration, invasion and metastasis of colon cancer cells. Int J Cancer 2018;143:921-30.

37. Satomi A, Murakami S, Hashimoto T, et al. Significance of superoxide dismutase (SOD) in human colorectal cancer tissue: correlation with malignant intensity. J Gastroenterol 1995;30:177-82.

38. Skrzydlewska E, Sulkowski S, Koda M, et al. Lipid peroxidation and antioxidant status in colorectal cancer. World J Gastroenterol 2005;11:403-6.

39. Dhillon AS, Hagan $S$, Rath $O$, et al. MAP kinase signalling pathways in cancer. Oncogene 2007;26:3279-90.

40. Thompson N, Lyons J. Recent progress in targeting the Raf/MEK/ERK pathway with inhibitors in cancer drug discovery. Curr Opin Pharmacol 2005;5:350-6.

41. Fresno Vara JA, Casado E, de Castro J, et al. PI3K/ Akt signalling pathway and cancer. Cancer Treat Rev 2004;30:193-204.

42. Mundi PS, Sachdev J, McCourt C, et al. AKT in cancer: new molecular insights and advances in drug development. Br J Clin Pharmacol 2016;82:943-56.

43. Fang Z, Tang Y, Jiao W, et al. Nitidine chloride inhibits 
renal cancer cell metastasis via suppressing AKT signaling pathway. Food Chem Toxicol 2013;60:246-51.

44. Aggarwal BB, Kunnumakkara AB, Harikumar KB, et al. Signal transducer and activator of transcription-3, inflammation, and cancer: how intimate is the relationship? Ann N Y Acad Sci 2009;1171:59-76.

45. Garcia R, Yu CL, Hudnall A, et al. Constitutive activation of Stat3 in fibroblasts transformed by diverse oncoproteins and in breast carcinoma cells. Cell Growth Differ 1997;8:1267-76.

46. Yu CL, Meyer DJ, Campbell GS, et al. Enhanced DNA-binding activity of a Stat3-related protein in cells transformed by the Src oncoprotein. Science 1995;269:81-3.

47. Tian SS, Tapley P, Sincich C, et al. Multiple signaling pathways induced by granulocyte colony-stimulating factor involving activation of JAKs, STAT5, and/or STAT3 are required for regulation of three distinct classes of immediate early genes. Blood 1996;88:4435-44.

48. Megeney LA, Perry RL, LeCouter JE, et al. bFGF and

Cite this article as: Gong H, Wang L, Zhao J, Wang L, Yu Q, Wan Y. Nitidine chloride inhibits the appearance of cancer stem-like properties and regulates potential the mitochondrial membrane alterations of colon cancer cells. Ann Transl Med 2020;8(9):591. doi: 10.21037/atm-20-3432
LIF signaling activates STAT3 in proliferating myoblasts. Dev Genet 1996;19:139-45.

49. Kim LH, Khadka S, Shin J-A, et al. Nitidine chloride acts as an apoptosis inducer in human oral cancer cells and a nude mouse xenograft model via inhibition of STAT3. Oncotarget 2017;8:91306-15.

50. Liao J, Xu T, Zheng JX, et al. Nitidine chloride inhibits hepatocellular carcinoma cell growth in vivo through the suppression of the JAK1/STAT3 signaling pathway. Int J Mol Med 2013;32:79-84.

51. Zhang L, Shao L, Creighton CJ, et al. Function of phosphorylation of NF-kB p65 ser536 in prostate cancer oncogenesis. Oncotarget 2015;6:6281-94.

52. Kim JS, Roberts JM, Bingman WE, et al. The prostate cancer TMPRSS2:ERG fusion synergizes with the vitamin D receptor (VDR) to induce CYP24A1 expression-limiting VDR signaling. Endocrinology 2014;155:3262-73.

53. Hoesel B, Schmid JA. The complexity of NF- $\kappa \mathrm{B}$ signaling in inflammation and cancer. Mol Cancer 2013;12:86. 